\title{
Does mismatch repair (MMR) deficiency have prognostic significance in low-risk
}

endometrioid endometrial cancers?

SR Kim ${ }^{1}$, A Pina ${ }^{2}$, A Albert ${ }^{3}$, JN McAlpine ${ }^{4,5}$, R Wolber 4,6 , B Gilks 4,6 , MS Carey 4,5 , JS Kwon ${ }^{4,5}$

1.Department of Obstetrics and Gynecology, Faculty of Medicine, University of British Columbia, Vancouver, BC, Canada

2. Department of Obstetrics and Gynecology, Division of Gynecology Oncology, Universite de Montreal, Montreal, QC, Canada

3. Women's Health Research Institute, Vancouver, BC, Canada

4. BC Cancer, Vancouver, BC, Canada

5. Department of Obstetrics and Gynecology, Division of Gynecologic Oncology, Vancouver, BC, Canada

6. Department of Pathology and Laboratory Medicine, University of British Columbia, Vancouver, BC, Canada

\section{BACKGROUND}

The mismatch repair (MMR) system is DNA repair mechanism that corrects base substitution mismatches that occur during DNA replication

Loss of MMR occurs in $20-40 \%$ of endometrial cancers, and this MMR deficiency can be detected via immunohistochemistry $(\mathrm{IHC})$ as loss of MMR protein expression

- $\quad$ Only $5-10 \%$ of endometrial cancers with MMR deficiency are due to Lynch Syndrome, due to autosomal dominant mutations in MLH1, MSH2, MSH6, or PMS2

Our previous work has demonstrated that in women with advanced endometrial cancer receiving adjuvant treatment, MMR deficiency is associated with better overall and progression-free survival as well as lower recurrence rates; this is theorized to be secondary to heightened response to adjuvant therapy

It remains uncertain whether MMR deficiency is prognostic or predictive of outcomes, as most patients in these studies had received adjuvant therapy

- To determine the prognostic value of MMR deficiency, we looked at a subgroup of women with low-risk

endometrioid endometrial cancer, for which there is usually no adjuvant therapy given after surgery

\section{OBJECTIVE}

To compare recurrence and survival outcomes in women with MMR-deficient endometrial cancers compared to those with

MMR-proficient cancers, specifically among those with low risk disease (Stage IA, grade 1 and 2, endometrioid histology)

\section{HYPOTHESIS}

By comparing low-risk MMR-deficient vs. MMR-proficient endometrioid endometrial cancers, we can better elucidate the prognostic value of MMR deficiency

\section{METHODS}

Study Design

Retrospective population-based cohort study

\section{Patient Cohort}

- $\quad$ Low-risk endometrial cancer cases (Endometrioid type, stage IA, grades 1 or 2 only using ESMO classification)

- $\quad$ Treated surgically from 2011 to 2016

- $\quad$ All evaluated for MMR deficiency via IHC (4 MMR proteins evaluated: $M L H 1, M S H 2, P M S 2, M S H 6$ )

- Total of 475 patients identified with 6 months of follow up

Data Analysis

- Demographics and clinical characteristics compared between patients with MMR-deficient and those with MMR proficient tumors

Fisher's exact test for categorical data

Wilcoxon rank-sum test for continuous data

Recurrence rates reported per 100 person-years

Progression free survival (PFS) and overall survival

(OS) compared using Kaplan-Meier curves and logrank tests

- Cox proportional hazards regression to estimate difference in PFS and OS after covariate adjustment

\begin{tabular}{|c|c|c|c|c|}
\hline \multicolumn{5}{|c|}{ RESULTS } \\
\hline & $\begin{array}{l}\text { TOTAL } \\
(475)\end{array}$ & $\begin{array}{c}\text { MMR- } \\
\text { PROFICIENT } \\
(\mathbf{3 4 4 )}\end{array}$ & $\begin{array}{c}\text { MMR- } \\
\text { DEFICIENT } \\
\text { (131) }\end{array}$ & P-VALUE \\
\hline $\begin{array}{r}\text { AGE AT DIAGNOSIS } \\
\text { (MEDIAN AND IQR) }\end{array}$ & $60(53-68)$ & $59(53-66)$ & $62(55-69)$ & 0.005 \\
\hline BMI (MEAN) & $35(+/-11)$ & $36(+/-11)$ & $32(+/-8)$ & 0.008 \\
\hline $\begin{array}{r}\text { POSTOPERATIVE } \\
\text { GRADE: }\end{array}$ & $\begin{array}{l}310(65 \%) \\
165(35 \%)\end{array}$ & $\begin{array}{l}244(71 \%) \\
100(29 \%)\end{array}$ & $\begin{array}{l}66(50 \%) \\
65(50 \%)\end{array}$ & $<0.0001$ \\
\hline LYMPHADENECTOMY & $42(8.8 \%)$ & $19(5.5 \%)$ & $23(17.6 \%)$ & $<0.0001$ \\
\hline LYNCH SYNDROME & $14(2.9 \%)$ & $0(0 \%)$ & $14(10.7 \%)$ & $<0.0001$ \\
\hline $\begin{array}{r}\text { MMR DEFICIENCY } \\
\text { MLH1/HYPERMETHYLA } \\
\text { TION } \\
\text { MSH2 } \\
\text { MSH6 } \\
\text { PMS2 }\end{array}$ & & & $\begin{array}{l}102(78 \%) \\
13(10 \%) \\
14(11 \%) \\
2(2 \%)\end{array}$ & \\
\hline ADJUVANT THERAPY & $30(6.3 \%)$ & $14(4.1 \%)$ & $16(12.2 \%)$ & 0.002 \\
\hline BRACHYTHERAPY & $10(2.1 \%)$ & $7(2.0 \%)$ & $3(2.3 \%)$ & 1.00 \\
\hline $\begin{array}{r}\text { PELVIC } \\
\text { RADIOTHERAPY }\end{array}$ & $13(2.7 \%)$ & $3(0.9 \%)$ & $10(7.6 \%)$ & 0.0003 \\
\hline $\begin{array}{r}\text { ADJUVANT } \\
\text { CHEMOTHERAPY }\end{array}$ & $13(2.7 \%)$ & $6(1.7 \%)$ & $7(5.3 \%)$ & 0.053 \\
\hline
\end{tabular}

FIGURE 1. MMR STATUS AND PROGRESSION FREE SURVIVAL (LEFT) AND OVERALL SURVIVAL (RIGHT) IN LOW-RISK ENDOMETRIAL CANCER

$P$ value is from log-rank test. MMR-proficient=red, MMR-deficient=blue. The shaded area indicates the $95 \% \mathrm{Cl}$.
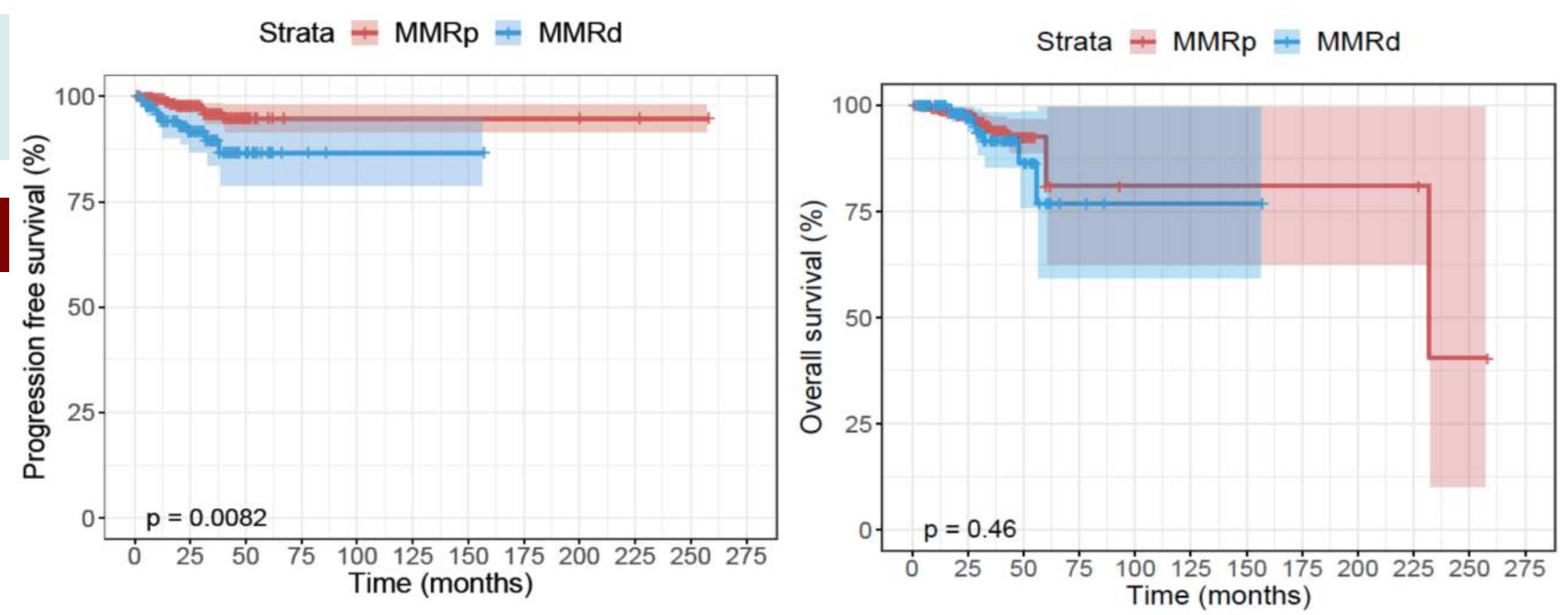

\section{SUMMARYICONCLUSIONS}

Women with MMR deficient tumors are older with lower BM

- Women with MMR deficient tumors are more likely to have undergone lymphadenectomy, and more likely to have lymphovascular space invasion identified in the tumors $(18 \%$ vs $6 \%, p<0.0001$ )

- Women with MMR deficient tumors had higher recurrence rates (3.56p100py) compared to those with MMR proficient tumors (1.21p100py) with $\mathrm{p}=0.008$

- Absolute recurrences were low, with 11 out of 131 in MMR-deficient and 14 out of 344 MMR-proficient groups

- After adjustment for age, LVSI status, adjuvant therapy, and post-operative grade, MMR-deficient status remained associated with a higher risk of recurrence (HR 3.56, 95\% Cl 2.01-5.95)

- $\quad$ Median follow-up was 23.4 months (11.7-40.6mo)

- MMR deficiency may have adverse prognostic value in low-risk endometrial cancers, as demonstrated by higher recurrence rates

- In contrast, MMR deficiency has been found to be a favorable predictive marker for response to adjuvant therapy as demonstrated by our previous study

- Worse outcomes associated with MMR deficiency may be related to dysregulation of estrogen and progesterone receptor 